\title{
Benefits of supplementary tube feeding after fractured neck of femur: a randomised controlled trial
}

\author{
M D BASTOW，J RAWLINGS，S P ALLISON
}

\begin{abstract}
A total of 744 elderly women with fractured neck of femur were classified into three groups according to anthropometric measurements on admission: group 1, well nourished; group 2, thin; group 3, very thin. Group 1 ate well and had a low mortality and a short rehabilitation time. The thinner the patients the lower their voluntary food intake, the higher their mortality and the longer their rehabilitation time.

$A$ series of 122 patients from groups 2 and 3 were entered postoperatively into a randomised controlled trial of overnight supplementary nasogastric tube feeding (4.2 MJ (1000 kcal), including $28 \mathrm{~g}$ protein) in addition to their normal ward diet. This treatment was associated with improvements not only in anthropometric and plasma protein measurements but also in clinical outcome, especially in the very thin group 3 patients. $\mathrm{Re}-$ habilitation time and hospital stay were shortened. Mortality in group 3 was less in the tube fed patients (8\%) than in the controls $(22 \%)$ but this difference did not reach statistical significance. One in five patients could not tolerate the nasogastric tube, but in the remainder the treatment caused no side effects and did not seriously diminish voluntary oral food intake by day.
\end{abstract}

\section{Introduction}

The effects of malnutrition on the morbidity and mortality of the sick have been recognised since the time of Hippocrates. In the classic study by Studley ${ }^{1}$ mortality in patients undergoing surgery for peptic ulcer was related to the amount of preoperative weight loss, and many later studies confirmed the association between undernutrition, morbidity, and mortality. Controlled studies showing clinical benefit of nutritional treatment are less easy to find, although anecdotes and assertions are plentiful. This may be due to the difficulties of assembling a sufficiently large and homogenous group of patients with non-malignant disease and evident undernutrition in whom supplementary feeding can be continued for an adequate period. Among the 600 elderly women admitted to this hospital each year with fractured femur there are many who appear to be undernourished. A formal study $^{2}$ showed that at least one fifth were severely undernourished, and these patients had a mortality of $20 \%$ as compared with $4 \%$ in the well nourished. This difference was independent of age or associated disease. The very thin appeared to be at particular risk of injury indoors in mid-winter, probably through a defect of thermoregulatory reflexes and consequent hypothermia. This paper describes a controlled trial of supplementary nasogastric feeding in this relatively homogeneous group of patients.

\footnotetext{
Department of Medicine, University Hospital, Queen's Medical Centre, Nottingham NG7 2 UH

M D BASTOW, BSC, MRCP, medical registrar

J RAWLINGS, SRD, research dietitian

S P ALLISON, MD, FRCP, consultant physician

Correspondence to: $\mathrm{Dr} M \mathrm{D}$ Bastow.
}

\section{Patients and methods}

During an 18 month period the nutritional state of $87 \%$ (744) of all elderly women admitted from the Nottingham area with fractured neck of femur was assessed by one observer (MB) within 48 hours of admission. As described, ${ }^{2}$ the patients were classified according to arm circumference and triceps skinfold thickness with reference to the mean and standard deviation of the home and hospital patients in the anthropometric study of Vir and Love. ${ }^{3}$ They were divided into three groups: group 1, well nourished (greater than or equal to the mean or less than one standard deviation below the mean); group 2, thin (one to two standard deviations below the mean); group 3, very thin (over two standard deviations below the mean).

Most patients underwent operation within 36 hours and all within three days of injury. By five days after injury they had been transferred to the orthopaedic rehabilitation ward.

Mortality - The effect of supplementary feeding on mortality during the period of hospital stay was recorded. Mortality after discharge from hospital was not recorded.

Food intake-The daily food intake during hospital stay was assessed by the technique validated by Hessov. ${ }^{4}$ Food was provided in standard portions under the supervision of the research dietitian (JR), and the amount served and the amount left at the end of each meal were recorded by the nursing staff on simple charts. Any snacks between main meals were noted.

Rehabilitation and hospital stay-Each patient's progress was documented by the ward physiotherapist. Record was made of the number of days between the patient's operation and the achievement of two goals: goal 1, weight bearing with support (one or two attendants for sitting to standing, some weight bearing by the affected leg, standing posture control present, walking with a frame with two attendants); goal 2, independent mobility (no help for sitting to standing, full weight bearing by the affected leg, walking independently with or without a frame for the width of the ward $(6 \mathrm{~m}))$. The decision to discharge the patient was taken independently by the consultant in charge.

Anthropometric data-Weight, upper arm circumference, and triceps skinfold thickness were recorded at weekly intervals for each patient throughout the study.

Haematological and biochemical measurements-Within 24 hours of admission venous blood samples were taken for estimation of haemoglobin and red cell indices (Coulter SII counter), serum albumin and transferrin concentrations (autoanalyser), and thyroid binding prealbumin concentration (Rocket electrophoresis). Plasma protein measurements were estimated daily during the first three weeks of the study and then three times a week.

Criteria for entry into feeding study-Only patients from groups 2 and 3-that is, thin or very thin-were entered into the supplementary feeding study. Patients incapable of understanding the nature of the treatment were excluded, as were those with severe dementia (score below 4 on the Camden scale ${ }^{5}$ ) or serious concomitant physical disorders-for example, stroke. Owing to administrative difficulties we could not monitor more than six patients simultaneously, so that no more were admitted to the study while the six feeding beds were occupied.

Protocol-If a patient met the criteria for entry and a vacancy existed she was randomly allocated to the supplementary feeding or control group. No patient was withdrawn once she had entered the study. Both control and tube fed patients ate a normal ward diet during the day and were given free access to snacks and drinks. The voluntary oral intake of each patient was charted carefully and the daily intake estimated. The patients' oral intake was used as a measure of appetite in attempting to answer the question whether overnight tube feeding diminished voluntary oral intake by day. Those in the supplementary feeding group received, in addition to a ward diet, an overnight feed of 1 litre Clinifeed Iso $(4 \cdot 2 \mathrm{MJ}$ (1000 kcal), including $28 \mathrm{~g}$ protein). This was started within five days of operation and delivered over eight hours each night through a fine bore $(1.5 \mathrm{~mm}$ external diameter) soft nasogastric tube using a peristaltic pump. The 
tube was left in place during the day, although it was disconnected from the feed reservoir. If the patient failed to tolerate the tube or removed it on three consecutive occasions treatment was stopped, although she remained in the tube fed group for statistical analysis. Otherwise tube feeding was continued until the patient was discharged from the ward or died.

Analysis of results-On being randomised to the supplementary feeding group the patient was treated statistically by intention to feed even if, for one reason or another, tube feeding could not be initiated or sustained. Data were analysed by Student's $t$ test (unpaired) or, when no assumption could be made about the normality of the distribution, by the Mann-Whitney $U$ test. The Fisher exact probability test was used for analysis of mortality during hospital stay.

\section{Results}

Sixty four patients were given supplementary tube feeding and there were 58 controls. The results are presented separately for each of the three nutritional assessment groups in order to illustrate any differences in the effect of treatment according to initial nutritional state.

Mortality was lower in the tube fed patients than in the controls in the very thin group 3 , but the difference did not reach statistical significance $(p>0 \cdot 1)$ (table I).

TABLE I-Number of patients, mean age, and mortality during hospital stay in each nutritional group

\begin{tabular}{|c|c|c|c|}
\hline Nutritional group & $\begin{array}{c}\text { No of } \\
\text { patients }\end{array}$ & $\begin{array}{c}\text { Mean age } \\
\text { in years (range) }\end{array}$ & $\begin{array}{l}\text { No (" } ") \\
\text { of deaths }\end{array}$ \\
\hline $2\left\{\begin{array}{l}\text { Control } \\
\text { Tube fed } \\
\text { Control } \\
\text { Tube fed }\end{array}\right.$ & $\begin{array}{l}21 \\
35 \\
39 \\
23 \\
25\end{array}$ & $\begin{array}{l}77(68-91) \\
78(69-89) \\
80(68-92) \\
82(74-89) \\
82(70-91)\end{array}$ & $\begin{array}{l}1 \quad(4 \cdot 8) \\
4(11 \cdot 4) \\
5(12 \cdot 8) \\
5(21 \cdot 7) \\
2(8 \cdot 0)^{*}\end{array}$ \\
\hline
\end{tabular}

*Difference not statistically significant.

Age and type of fracture-There was no difference in age among the three nutritional groups or between those in each group who were tube fed and those who served as controls (table I). The various types of fracture of the femoral neck and the associated methods of interna fixation were evenly distributed among the nutritional groups. There was no difference in dementia score or incidence of associated diseases between treated patients and controls.

Food intake-Table II shows the patients' mean daily voluntary food intake and the duration of overnight feeding. Oral food intake correlated with nutritional state on admission, the thin and very thin patients tending to eat less than the well nourished group $(\mathrm{p}=0.007$ ).

TABLE II-Daytime voluntary oral intake and duration of overnight tube feeding

\begin{tabular}{llc}
\hline Nutritional group & $\begin{array}{c}\text { Mean oral energy intake in } \\
\text { MJ (SD) }\end{array}$ & $\begin{array}{c}\text { Median duration of tube } \\
\text { feeding in days (range) }\end{array}$ \\
\hline 1 & $7 \cdot 6(2 \cdot 0)$ & \\
$2 \begin{cases}\text { Control } \\
\text { Tube fed }\end{cases}$ & $5 \cdot 7(1 \cdot 2)$ & \\
$3\left\{\begin{array}{l}\text { Control } \\
\text { Tube fed }\end{array}\right.$ & $4 \cdot 2(1 \cdot 5)^{*}$ & $24(17-31)$ \\
\hline
\end{tabular}

*Mann-Whitney $\mathrm{U}$ test: $\mathrm{p}=0.02$

Conversion: SI to traditional units-Energy: $4 \cdot 2 \mathrm{MJ} \approx 1000 \mathrm{kcal}$

Only in group 2 was overnight nasogastric tube feeding associated with a small, but statistically significant ( $p=0.02$ ), reduction in the patient's voluntary food intake as compared with that of the controls. There was no significant difference in the pattern of appetite recovery between the control and tube fed patients after operation. Roughly one third of the patients who received overnight supplementation were fed for less than five days, either because they could not tolerate the nasogastric tube (14 cases) or because they died (seven). These patients are included in the calculation of oral intake in table II but excluded from the calculation of duration of feeding. The greater food intake of the already well nourished group 1 than of groups 2 and 3 was largely due to snacks and drinks between meals. There was a notable lack of such voluntary supplementation in the very thin patients.

Rehabilitation and hospital stay-Table III shows the time taken to achieve goals 1 and 2 . There was no difference between tube fed patients and controls in the time taken to achieve goal 1 . The length of time taken to achieve goal 2 was related to the degree of thinness and was significantly shortened by supplementary tube feeding. The numbers reaching goal 2 were diminished by deaths, particularly in group 3. Domestic and social factors, rather than the achievement of independent mobility, appeared to be major determinants for the duration of hospital stay. There was, however, a small reduction in hospital stay in the tube fed patients in group 3 compared with the controls (median hospital stay 29 days compared with 38 days, $\mathrm{p}=0.04$ (patients who died before discharge included)).

TABLE III-Rehabilitation time for each nutritional group

\begin{tabular}{lccc}
\hline \multirow{2}{*}{\begin{tabular}{c} 
Nutritional group \\
\cline { 2 - 4 }
\end{tabular}} & \multicolumn{2}{c}{ Median rehabilitation time in days (range) } \\
\cline { 2 - 4 } & goal 1 & Goal 1 to & $\begin{array}{c}\text { Operation to } \\
\text { goal 2 }\end{array}$ \\
\hline 1 & $7(3-17)(n=21)$ & $6(1-18)(n=20)$ & $10(5-28)(n=20)$ \\
$2\left\{\begin{array}{l}\text { Control } \\
\text { Tube fed }\end{array}\right.$ & $6(2-22)(n=35)$ & $8(2-17)(n=30)$ & $12(5-26)(n=30)$ \\
& $6(2-15)(n=39)$ & $4(1-11)^{*}(n=38)$ & $10(4-20)+(n=38)$ \\
$3\{$ Control & $11(4-29)(n=23)$ & $12(6-26)(n=19)$ & $23(10-45)(n=19)$ \\
Tube fed & $8(2-23)(n=25)$ & $7(3-14)^{*}(n=22)$ & $16(5-34)^{*}(n=22)$
\end{tabular}

${ }^{*}+$ Mann-Whitney $U$ test : ${ }^{*} \mathrm{p}=0.02 ; \mathrm{p}=0.04$

Anthropometric data-Table IV shows the change in weight, upper arm circumference, and triceps skinfold thickness. Tube feeding caused an increase in these measurements in the thin group 2 , but only the change in mid-arm circumference reached statistical significance. More striking and significant improvement occurred in the very thin group 3.

TABLE IV-Change in anthropometric measurements in each group

\begin{tabular}{|c|c|c|c|}
\hline Nutritional group & $\begin{array}{l}\text { Mean (SD) change } \\
\text { in weight }(\mathrm{kg})\end{array}$ & $\begin{array}{l}\text { Mean (SD) change } \\
\text { in triceps skinfold } \\
\text { thickness }(\mathrm{mm})\end{array}$ & $\begin{array}{l}\text { Mean (SD) change } \\
\text { in mid-arm } \\
\text { circumference }(\mathrm{cm})\end{array}$ \\
\hline $\begin{array}{l}2 \\
3\end{array}\left\{\begin{array}{l}\text { Control } \\
\text { Tube fed } \\
\text { Control } \\
\text { Tube fed }\end{array}\right.$ & $\begin{array}{l}+2.4(2.7) \\
+1.2(3.1) \\
+2.8(1.9) \\
+0.7(2.6) \\
+4.9(2.3)^{*}\end{array}$ & $\begin{array}{l}+2 \cdot 3(3 \cdot 8) \\
+1 \cdot 7(2 \cdot 9) \\
+2 \cdot 6(3 \cdot 1) \\
+2 \cdot 4(3 \cdot 2) \\
+4 \cdot 1(1 \cdot 7)^{*}\end{array}$ & $\begin{array}{l}+1 \cdot 2(1 \cdot 5) \\
+0.7(1.9) \\
+1 \cdot 0(1 \cdot 4) \dagger \\
+0.3(2 \cdot 1) \\
+1.3(1.1)^{*}\end{array}$ \\
\hline
\end{tabular}

*+Unpaired $t$ test: ${ }^{*} \mathrm{p}<0.01 ;+\mathrm{p}=0.02$

Haematological and biochemical measurements-On admission the mean haemoglobin concentrations in groups 1,2 , and 3 were 12.6 , $12 \cdot 0$, and $10 \cdot 1 \mathrm{~g} / \mathrm{dl}$ respectively, the value in group 3 being significantly different from those in the other groups at the $5 \%$ level. There was no clear difference in subsequent trends, however, between tube fed and control patients in haemoglobin concentration, packed cell volume, or urea or electrolyte values. There was no difference in serum albumin concentration between groups 1 and 2 . This value, however, was signi-

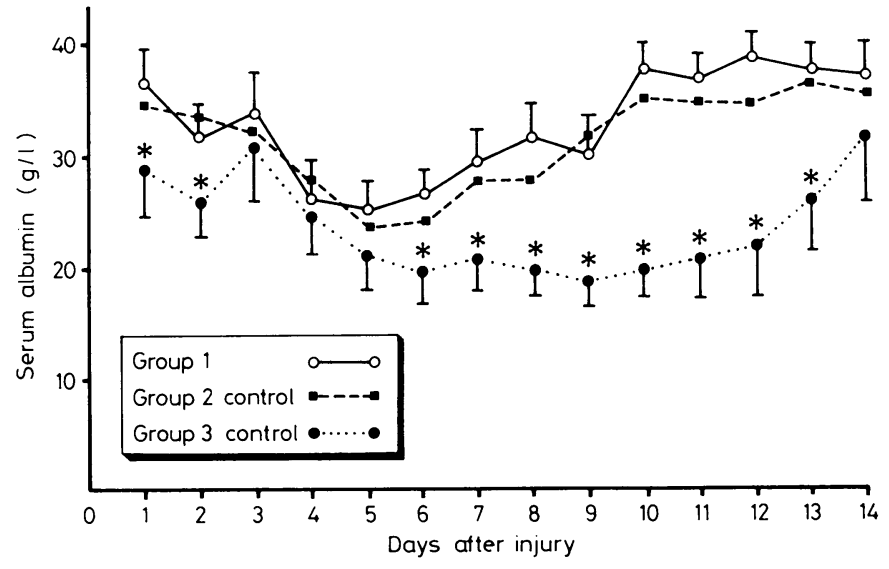

FIG 1 -Serial measurements of mean serum albumin concentrations in the three groups. Bars represent SD.

*Student's $t$ test (unpaired): $\mathrm{p}<0.01$. 
ficantly lower on admission in group 3 than in group $1(p=0.03)$ and the rise to normal after operation was much slower (fig 1). This trend was not significantly affected by perioperative blood transfusion or postoperative tube feeding. The shorter half life protein, thyroid binding prealbumin, showed a similar pattern (fig 2) of difference between groups 1 and 3, but the tube fed patients in group 3 showed a more rapid recovery in the serum concentration after operation.

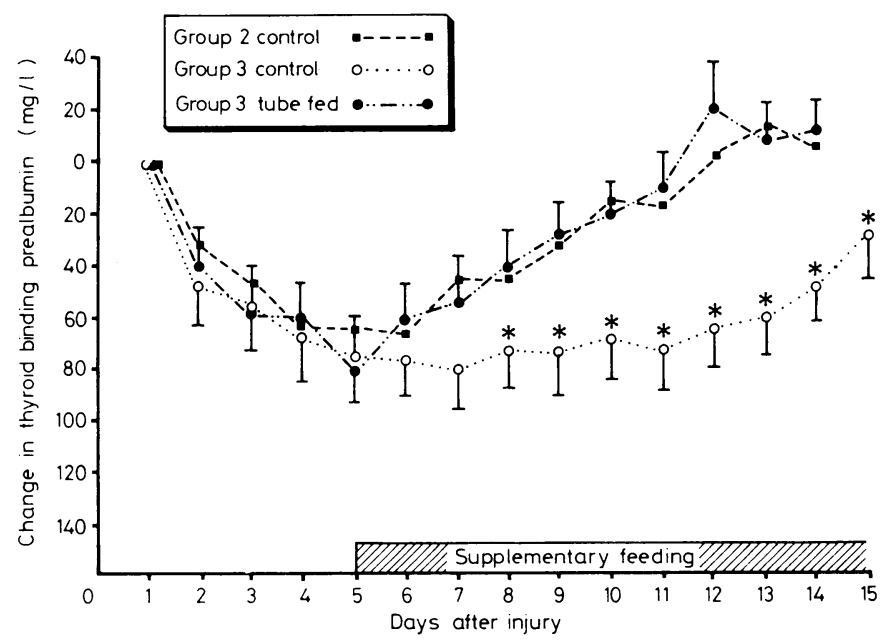

FIG 2-Serial changes in serum thyroid binding prealbumin concentrations in groups 2 (control) and 3 (control and tube fed). Points are means. Bars represent SD.

*Student's $t$ test (unpaired): $\mathrm{p}<0.01$

Complications-Of the 64 patients allocated to receive overnight supplementation, $14(22 \%)$ failed to tolerate the nasogastric tube. In the remainder, who did tolerate the tube, however, the incidence of side effects was minimal. Aspiration of feed did not occur. Diarrhoea was unusual and if present was invariably associated with concomitant oral antibiotic treatment. ${ }^{6}$

\section{Discussion}

In this study overnight nasogastric tube feeding was well tolerated by $78 \%$ of elderly women with fractured femur and was associated with an appreciable reduction in the time taken to achieve independent mobility. The study provides a basis for selecting patients likely to benefit from supplementary nutrition. The high oral food intake of the well nourished patients and the low oral intake of the thin patients after operation has been discussed elsewhere. ${ }^{2}$ This difference in behaviour widens the nutritional gap further and emphasises the importance of patient selection in determining the outcome of any prospective nutritional study. Those whose anthropometric measurements were within one standard deviation of the reference range ate well after operation and had a short rehabilitation time. Those below these limits ate poorly and had a longer rehabilitation time, which was shortened by supplementary feeding nearly to that seen in the previously well nourished group 1 . The failure of treatment to affect the time taken to achieve goal 1 was not surprising, since the mean time from operation to start of treatment was four days (roughly half the time taken to achieve goal 1 in the untreated patients).

Although mortality appeared to be diminished by tube feeding in the very thin group 3, this difference was not statistically significant. It would have required about three times the number of patients in the study in order for the difference in mortality between tube fed patients $(8 \%)$ and controls $(22 \%)$ to reach statistical significance at the $5 \%$ level.

These clinical effects of treatment were accompanied by significant increases in weight, arm circumference, and skinfold thick- ness, especially in the very thin group 3 . The expected fall in serum albumin, prealbumin, and transferrin concentrations associated with acute illness was seen in all patients. ${ }^{7} 8$ The recovery of serum albumin to normal was faster in the normally nourished group 1 than in the thinner patients, but this was unaffected by tube feeding. Like Carpentier $e t a l,{ }^{8}$ we found that the shorter half life (about two days) of thyroid binding prealbumin makes it a far more sensitive marker of the response to nutritional treatment than albumin. Transferrin proved unreliable as a nutritional guide, presumably because it is additionally influenced by iron state. ${ }^{9}$ There was no obvious pattern in the haematological measurements, which were, in any case, affected by perioperative transfusion.

Urea and electrolyte concentrations were similarly inconsistent. Arguably the beneficial effects of tube feeding were partly due to salt and water administration. Ideally, the controls should have received overnight tube supplementation with salt and water but for several reasons this was impracticable. There is no reason to believe, however, that the controls lacked salt or water, since they were well nursed in special rehabilitation wards. Also there was no difference in packed cell volume between treated patients and controls within each group, which would have been expected had there been appreciable differences in extracellular fluid volume. The rise in prealbumin concentrations in the tube fed patients would be inconsistent with the effect of salt and water only.

Overnight tube feeding was associated with a small reduction in voluntary oral intake during the day, but the sum of tube feed and oral intake in the thin groups almost equalled the voluntary oral intake in the well nourished group 1. This agrees with the findings of Ashworth et al, ${ }^{10}$ who reported that overnight tube feeding with $8.4 \mathrm{MJ}$ (2000 kcal) for up to 36 days did not suppress voluntary food intake during the day. Yeung et al showed that jejunostomy feeding also did not suppress oral intake in postoperative patients. ${ }^{11}$ These observations contrast with the results of Bangerjee et al, ${ }^{12}$ who found that supplementary sip feeding by day with Complan produced a reduction in elderly patients' voluntary food intake sufficient to nullify any potential benefit.

The fact that in our study supplementary food was given by tube overnight and not by day may have been important.

Despite the widespread use of enteral and parenteral nutrition in the supportive treatment of surgical and medical patients, most reports on the subject are devoted to the effect of this treatment on nutritional variables, and those which attempt to measure clinical benefit are largely uncontrolled. The few controlled studies have, in the main, been devoted to malignant disease. ${ }^{13}$ The optimistic conclusions of uncontrolled studies of parenteral feeding in patients undergoing chemotherapy and radiotherapy have been denied by subsequent controlled trials. ${ }^{14-17}$ On the other hand, randomised prospective trials of preoperative parenteral nutrition in patients with cancer have shown benefit in terms of morbidity and possibly mortality. ${ }^{18}$ Mullen et al carried out an essentially uncontrolled study of parenteral nutrition on a heterogeneous group of surgical patients $^{19}$ which suggested clinical benefit of preoperative nutrition; but the lack of randomisation-as the authors themselves pointed out-made their results inconclusive. Sagar et $a l$ in a randomised study measured the effect of early postoperative tube feeding in patients undergoing abdominal surgery. ${ }^{20}$ There was a significant beneficial effect of treatment on nutritional variables and on shortening hospital stay. These and our results suggest some benefit of nutritional treatment in shortening recovery from acute illness.

We express our thanks for the help received during this study from Ms $M$ Churton and Mr T Hutchinson and other members of the orthopaedic physiotherapy staff. We are most grateful for all the help and cooperation we have received from the medical and nursing staff of the orthopaedic wards, without which the study would have been impossible. We thank Miss M McLean for secretarial help. MDB was supported by a grant from Roussell Laboratories Ltd. 


\section{References}

1 Studley HO. Percentage of weight loss, a basic indication of surgical risk in patients with chronic peptic ulcers. FAMA 1936;106:458-60.

- Bastow MD, Rawlings J, Allison SP. Undernutrition, hypothermia and injury in elderly women with fractured femur; an injury response to altered metabolism? Lancet 1983;i:143-6.

${ }^{3}$ Vir SC, Love AHG. Anthropometric measurements in the elderly. Gerontology $1980 ; 26: 261-8$.

- Hessov IB. Detecting deficient energy and protein intake in hospital patients: a simple record method. Br Med f 1978; : 1667-8.

${ }^{5}$ Denham MJ, Jeffreys PM. Routine mental testing in the elderly. Modern Geriatric $1972 ; 2: 275-7$.

${ }^{6}$ Woolfson AMJ, Ricketts CR, Hardy SM, Saour JN. Prolonged nasogastric tube feeding in critically ill and surgical patients. Postgrad Med 于 $1976 ; 52: 678-82$.

${ }^{7}$ Moore PJ, Clark RG. Colloid osmotic pressure and serum albumin following surgery. Br 7 Surg 1982;69:140-2.

${ }^{8}$ Carpentier YA, Barthel J, Bruyns J. Plasma protein concentration in nutritional assessment. Proc Nutr Soc 1982;41:405-17.

${ }^{9}$ Shetty PS, Jung RT, Pollard BJ, Allison SP, Watrasiewicz KE, James NPT. Rapid turn-over transport problems: an index of subclinical protein energy malnutrition. Lancet 1979; ii :230-2.

10 Ashworth N, Creedy S, Hunt JN, Mahon S, Newland P. Effect of nightly food supplements on food intake in man. Lancet $1962 ; \mathrm{ii}: 685-7$.

11 Yeung CK, Young GA, Hackett AF, Hill GL. Fine needle catheter jejunostomy-an assessment of a new method of nutritional support after major gastrointestinal surgery. Br f Surg 1979;66:727-32.
${ }^{12}$ Bangerjee AK, Brocklehurst JC, Wainwright $\mathrm{H}$, Swindell R. Nutritional status of long stay geriatric inpatients: effects of a food supplement (Complan). Age Ageing 1978;7:237-43.

${ }^{13}$ Hoffer AR, Fischer JE. The effects of perioperative hyperalimentation on complications in patients with carcinoma and weight loss. $\mathcal{F}$ Surg Res $1977 ; 23: 31-4$.

14 Copeland EM, Dudrick SJ. Nutritional aspects of cancer. Curr Probl Cancer 1976;1:1-51.

${ }^{15}$ Dudrick SJ, Copeland EM, McFadyen BV. The nutrtitional care of the cancer patient. In: Green IM, ed. Current concepts in parenteral nutrition. The Hague: Nijhoff Medical Division, 1977:1987-2216.

${ }^{16}$ Nixon DW, Moffitt S, Olkowski Z, et al. Parenteral nutritional supplementation in cancer. In: Howard AN, Mclean Baird I, eds. Recent advances in clinical nutrition 1. London: John Libbey, 1981:183-4.

17 Bothe A, Valerio D, Bistrian BR, Blackburn GL. Randomised controlled trial of hospital nutritional support during abdominal radiotherapy. Fournal of Parenteral and Enteral Nutrition 1979;3:292-6.

${ }^{18}$ Heatley RV, Williams RHP, Lewis MH. Pre-operative intravenous feeding -a controlled trial. Postgraduate Med f 1979;55:541-5.

${ }^{9}$ Mullen JL, Buzby GP, Matthews DC, Smale BF, Rosato EF. Reduction of operative morbidity and mortality by combined preoperative and postoperative nutritional support. Ann Surg 1980;192:604-13.

20 Safar S, Harland P, Shields R. Early postoperative feeding with elemental diet. Br Med f 1979;i:293-5.

(Accepted 7 September 1983)

\section{SHORT REPORTS}

\section{Safety of zimeldine in overdose}

Zimeldine, which has highly selective effects on serotonergic receptors, is an effective treatment for depressive illness. ${ }^{1}$ Because of its selective receptor specificity few side effects, especially on the cardiovascular system, have been reported. In one case of overdosage only minor flattening of $T$ waves was observed on the electrocardiogram. ${ }^{2}$ Postural hypotension, which may limit the dosage of other antidepressants, particularly in the elderly is less common with zimeldine. ${ }^{1}$ We report a case of zimeldine overdose that confirms the above observation.

\section{Case report}

A 29 year old married woman had suffered from agoraphobia for four years and more recently had been depressed. Treatment with zimeldine was started at a dose of $100 \mathrm{mg}$ at night and was increased one week later to $200 \mathrm{mg}$. Her depression improved and she was discharged to outpatient care.

Three months later she was admitted to the coronary care unit three hours after taking $5.2 \mathrm{~g}$ zimeldine. Gastric lavage was performed, but no tablets were returned. She complained of nausea, dizziness, and pain in the right side of her abdomen. On examination she was alert and orientated. Her pupils were dilated but reacting; there was considerable horizontal nystagmus. Examination of the peripheral nervous system showed bilateral pronounced coarse tremor exacerbated by movement. There was bilatera increase in tone in her arms and legs, which also showed pronounced hyperreflexia and incoordination; Babinski responses were plantar. Abdominal examination showed no abnormality other than tenderness in the right hypochondrium. Cardiovascular examination was normal apart from tachycardia (heart rate 120 beats/minute). Blood pressure was $120 / 85 \mathrm{~mm} \mathrm{Hg}$ and there was no postural change.

Eight hours after ingestion of the tablets blood samples were taken for assessment of electrolyte concentrations, renal function, liver function, and serum concentration of zimeldine. These tests were repeated daily for three days, one week after overdose, and at one month of follow up. No abnormality was noted in haematological variables, renal function, serum bilirubin concentration, or results of urine analysis. Liver function tests showed a small rise in activities of aspartate transaminase, alanine transaminase, and $\gamma$-glutamyltransferase, although all remained within the normal range. Twenty four hour cardiac monitoring showed no abnormality, and the prolongation of the PR interval and tachycardia seen on her electrocardiogram on admission returned to normal within eight hours. Daily electrocardiography showed no further changes. Ventricular function was measured on days 1 and 6 with a portable nuclear probe and showed no impairment of ventricular contractility. The figure shows that eight hours after overdose the serum concentration of zimeldine was $11544 \mathrm{nmol} / \mathrm{l}(367099 \mathrm{ng} / 100 \mathrm{ml})$ and of norzimeldine $4233 \mathrm{nmol} / 1(128683 \mathrm{ng} / 100 \mathrm{ml}$ ) (measured by high pressure liquid chromatography ${ }^{3}$ ); these concentrations are far higher than those seen with therapeutic doses of zimeldine. ${ }^{4}$ By day 6 the serum concentration of zimeldine was zero and of norzimeldine $675 \mathrm{nmol} / \mathrm{l}(20520 \mathrm{ng}$ / $100 \mathrm{ml}$ ).

Lumbar puncture performed 16 hours after overdose showed substantial penetration of the drug into the cerebrospinal fluid, with concentrations of $828 \mathrm{nmol} / 1(26330 \mathrm{ng} / 100 \mathrm{ml})$ zimeldine and $858 \mathrm{nmol} / \mathrm{l}(26083 \mathrm{ng} / 100 \mathrm{ml})$ norzimeldine. An electrocardiogram recorded at that time showed mild slowing of the alpha rhythm but no epileptic discharges or focal features.

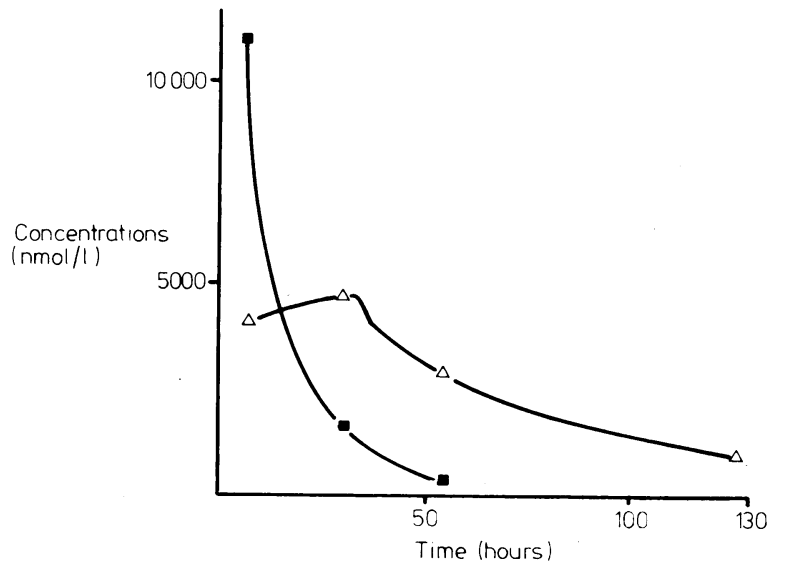

Plasma concentrations of zimeldine $(\mathbf{\square}-\mathbf{v})$ and norzimeldine $(\triangle-\Delta)$ after overdose of $5.2 \mathrm{~g}$ zimeldine.

Conversion: SI to traditional units-Zimeldine: $1 \mathrm{nmol} / 1 \approx 32 \mathrm{ng} / 100 \mathrm{ml}$ Norzimeldine: $1 \mathrm{nmol} / \mathrm{l} \approx 30 \mathrm{ng} / 100 \mathrm{ml}$.

Neurological signs resolved within 24 hours, but nausea and abdominal tenderness persisted until day 3. She was discharged on day 6 and was well when reviewed one month later.

\section{Comment}

This case supports claims for the low incidence of adverse effects of zimeldine, particularly its low cardiotoxicity. Broadening of the QRS complex by $100 \mathrm{~ms}$ or more is usually seen in overdose with tricyclic antidepressants ${ }^{5}$ but was not observed here, nor were there any other electrocardiographic changes indicative of overdosage of antidepressants. At no time did the patient complain of dry mouth, 